\title{
Cognition, social cognition, and Self-assessment in schizophrenia: prediction of different elements of everyday functional outcomes
}

\author{
Juliet Silberstein, ' and Philip D. Harvey ${ }^{1,2 *}$
}

\author{
${ }^{1}$ University of Miami Miller School of Medicine, Miami, FL, USA \\ ${ }^{2}$ Research Service, Bruce W. Carter VA Medical Center, Miami VA Healthcare System. Miami, FL, USA
}

A growing body of research has shown that two domains of cognition, neurocognition and social cognition, predict different domains of real-world outcomes in people with schizophrenia. Social cognition has been shown to predict social outcomes but not non-social outcomes (e.g. living independently), and neurocognition provides minimal prediction of social outcomes (e.g. interpersonal relationships). The differing predictive value of neurocognition and social cognition has led to an exploration of potential factors that interact with cognition to influence everyday outcomes. Functional skills, negative symptoms, and self-assessment have shown particularly promising relationships with cognitive ability. Several consensus studies have pinpointed valid performance-based assessments. High-contact informant ratings have additionally been shown to be highly accurate. The emerging understanding of divergent patterns of predicting outcomes and reliable assessments present an opportunity to improve treatment targets and realworld outcomes for individuals with schizophrenia. In particular, a recently defined component of metacognition has shown particular promise. Introspective accuracy (IA) addresses how well individuals evaluate their own abilities. Emerging research has found that IA of neurocognitive ability better predicts everyday functional deficits than scores on performance-based measures of neurocognitive skills and has found that IA of social cognition accounts unique variance in real world disability above social cognitive abilities. Intriguingly, IA of neurocognition appears to preferentially predict non-social outcomes while IA of social cognition predicts social outcomes.

Received 6 January 2018; Accepted 24 September 2018; First published online 26 January 2019

Key words: Schizophrenia, Cognition, Social Cognition, Functional Outcome, self-assessment.

Evidence has consistently shown that cognitive ability is a significant predictor of critical aspects of functional status in people with schizophrenia, including work performance and independent living skills. Appreciation of the cognitive deficits related to schizophrenia is not new, but for decades cognition was considered peripheral to psychosis and social withdrawal symptoms. However, when Bleuler coined the term "Schizophrenia" in the late $19^{\text {th }}$ century, he referred to deficits in "associative" thinking as "fundamental" to the disease. ${ }^{1}$ A century later cognition has again become central to our understanding of Schizophrenia, particularly in terms of the role cognitive limitations have in the development and maintenance of deficits in everyday activities. Performance

* Address correspondence to: Philip D. Harvey, PhD, Department of Psychiatry and Behavioral Sciences, University of Miami Miller School of Medicine, Miami, FL, USA 33136.

(Email: Philipdharvey1@cs.com) on tests of cognition and of the ability to perform everyday functional skills appear to be globally related to functioning and are more relevant to impairments in functioning than the severity of psychosis in most studies. ${ }^{1-8}$

Despite marked improvements in treatments of positive symptoms due to antipsychotic medications, functional deficits across objective (e.g., living independently, maintaining employment, and building relationships) and subjective domains (e.g., quality of life, perceived illness burden) remain a debilitating reality for the majority of individuals with schizophrenia. ${ }^{9}$ The associations between specific cognitive, competence and negative symptoms domains provide clinicians with more granularly defined deficits to probe. The subsequent discussion will focus on modes of assessments and their clinical implementation to target treatment.

Efforts to understand the relationship between cognition and outcomes in Schizophrenia have focused on 
neurocognition and more recently social cognition. Substantially, $70-75 \%$ of individuals with schizophrenia perform below the normative expectations on processing speed, attention, learning and memory, and problemsolving and working memory. These non-social cognitive domains fall under the broad label of neurocognition. In addition to deficits in the ability to live independently and engage in productive activities, patients may additionally struggle to function socially.

Social cognition has recently been identified as a candidate domain to understand social outcomes in healthy and impaired populations. An individual's ability to identify and interpret other's emotions or intentions, and to use those social signals to guide informed conclusions or behaviors fall under the broad category of social cognition. Social cognition is a newer domain of research with newer measures, many of which lack the rich history of validation and normative study of neurocognitive measures. ${ }^{10}$ As result, it is not yet possible to make a definitive statement about the prevalence of social cognitive impairments seen in people with schizophrenia.

Research on the association of cognition and functional outcomes has substantially deepened our understanding of both the nature and predictors of everyday outcomes, yet studies of the determinants of everyday functional deficits in schizophrenia have stalled at accounting $50 \%$ or less of the variance in real-world functioning. ${ }^{2-5}$ The attempts to determine additional associations between global neurocognition and outcome have been limited in their success. The Cognitive Neuroscience Test Reliability and Clinical Applications for Schizophrenia (CNTRACS) Consortium identified a number of cognitive abilities that were reliably measures with performance-based assessments and linked to specific elements of brain functioning. However, the consortium was not as successful at identifying predictive measures that added to the understanding of the causes of everyday disability despite using highly selective neuroscienceoriented tests with clear neurobiological correlates. ${ }^{11}$

On the surface these findings seem disheartening, but there are at least two reasons for this outcome. The first is the simplest, the more cognitive domains that a specific neuropsychological test predicts, the more globally sensitive it is to outcome. The classic example is that of various coding tests. These tests require intact functioning in several domains in order to be performed efficiently, including visual perception, problem solving, working memory, and speed. ${ }^{12}$ Thus, these tasks routinely account for more than $60 \%$ of the variance in composite measures of neurocognition ${ }^{13}$ and are routinely found to be the strongest predictor of everyday disability. ${ }^{14}$ Thus, tasks that measure a single highly selective aspect of cognitive performance seem unlikely to add to the prediction of the everyday disability by broad and nonspecific tests already capturing multiple cognitive domains.
The second reason is related to the development that a growing body of research has shown a divergence of neurocognition and social cognition for the prediction of different domains of real-world outcomes, such that social cognition predicts social outcomes but not everyday activities (e.g. living independently), and neurocognition provides a minimal prediction of social outcomes (e.g. interpersonal relationships). ${ }^{6,15}$ A recent study by Pinkham et.al. found that combined neurocognition and social cognition accounted for $13 \%$ of the variance in functional outcomes (social and nonsocial) as rated by high-quality informants. When the outcomes domains were differentiated, neurocognition accounted for only $5 \%$ of the variance in social outcomes. ${ }^{16}$ The differing predictive value of neurocognition and social cognition has led to an exploration of potential mediators, associated factors, and cognitive sub-domains that interact with cognition to influence everyday outcomes across the three main domains of functioning.

\section{Consensus Determination of Validated Tools to Assess Cognitive and Functional Deficits}

Several assessment issues have become apparent as cognition and social cognition have developed into important treatment targets. In contrast to assessment strategies that would be employed in less impaired populations, assessment of cognition, social cognition, functional capacity, and everyday functioning pose special challenges in people with people with schizophrenia. Self-report and, perhaps surprisingly, family or friend reported assessments of an individual with schizophrenia's cognitive ability and everyday functioning has yielded limited association to objective functioning as measured on performance-based assessments or achievement of functional milestones. ${ }^{17,18}$ The lack of validity of self-ratings of cognitive and functional ability have enhanced the need for reliable and clinicallyfeasible measures to examine cognitive abilities.

Several consensus initiatives have attempted to develop well-validated measures suitable for both use in clinical trials and treatment. The Measurement and Treatment Research to Improve Cognition in Schizophrenia (MATRICS) project ${ }^{19}$, was aimed at the need for standardized methods for the assessments of outcomes in studies aimed at the development of treatments of cognitive impairment associated with schizophrenia. Our research projects, SCOPE $^{10}$ and VALERO ${ }^{5}$, aimed to increase the validity of assessments of social cognition and functional outcomes, respectively. The outcome of these consensus projects has provided clinicians with valid methods that do not form treatment targets based on patients' self-reports and reports of non-caregiver relatives or friends of patients, which have shown lack requisite validity for use in either clinical trial or clinical treatment 
contexts. ${ }^{17,18}$ Assessment strategies in clinical trials and clinical practice fall in several different domains. These include performance-based assessments of cognition, social cognition, functional capacity, and social competence, as described above. Across domains of cognition, and everyday functioning, high contact clinician's or caregiver's evaluations and ratings have been shown to be highly aligned with performance measures. ${ }^{17}$ The implementation of performance-based and high-contact informant ratings can help clinicians create more targeted treatment goals.

\section{Introspective Accuracy}

Self-report of ability and functioning continues to add clinical value, despite the lack of validity for objective outcomes (Table 1). There has been recognition that the ability to evaluate one's own cognitive abilities, referred to often as "meta-cognition" is an important cognitive ability on its own. Over- or under- estimation of one's ability are both manifestations of impaired meta-cognitive functioning. A newly defined component of the larger metacognition construct addresses just how well individuals evaluate their own abilities and performance, ${ }^{20}$ and we refer to this type of self-awareness as "introspective accuracy" (IA). Selfreports lie at the crux of clinically assessing IA. Impairments in IA can be easily indexed by discrepancies between how one rates one's abilities and achievements, and his/ her actual performance or a high-contact informant's rating of his/her ability. Poor performers could be helped to attempt to match their aspirations to accomplishments and improve over time. Good performers could have their functioning bolstered by recognition of their competence. Thus, even a population whose performance often is poor could benefit from accurate self-assessment and reduce challenges from inaccurate self-evaluation. ${ }^{21}$

Importantly, a growing body of research has found that IA deficits across various domains have negative consequences on morbidity and mortality as these impairments impact medication adherence, suicidality, everyday activities, vocational functioning, and social outcomes. ${ }^{22-25}$ IA of neuro- and social- cognition appear to predict everyday functional outcomes differentially. IA of neurocognition preferentially predicts non-social everyday functional outcomes while IA of social cognition predicts real world social outcomes. Information obtained regarding IA of performance can be clinically helpful, regardless of whether performance is objectively good or bad.

\section{Varying Patterns of Predictions between Neuro- and Social Cognitive Assessments}

Objective assessment-based performance, informant ratings, and IA of neuro- and social cognition have all been shown to be associated with functional outcomes to differing extents. The subsequent discussion summarizes current findings on the patterns of prediction of function outcomes.

\section{Neurocognitive objective performance}

Scores on neurocognitive assessment batteries account for variation in non-social outcomes more strongly than social outcomes. A recent analysis found that performance of the consensus neurocognitive assessment battery (MCCB) accounted for $10 \%$ of the variance in everyday activities, $4 \%$ of the variance in vocational outcomes, and failed to account for variance in interpersonal relationships. ${ }^{26}$ Considering that vocational outcomes require both neuro- and social- cognitive ability, the relative strength of association decreased as the outcomes became more socially orientated.

IA of neurocognitive ability has been shown to be a more potent predictor of everyday functional deficits than scores on performance-based measures of neurocognitive cognitive abilities or functional capacity. Our VALERO study assessed the relative predictive power of neurocognitive IA, functional capacity (skills), and neurocognitive performance with three domains of functional outcomes (Table 2). The functional outcomes domains consisted of non-social (everyday activities), mixed non-social and social (work), and social outcomes (interpersonal). The analysis for everyday activities showed that IA accounted for $42 \%$ $\left(\mathrm{R}^{2}=.42, \mathrm{~F}=107.62, \mathrm{p}<.001\right)$ of the variance and neurocognitive performance contributed an additional $3 \%$ of the variance $\left(\mathrm{R}^{2}=.45, \mathrm{~F}=60.22, \mathrm{p}<.001\right)$. When vocational outcomes were analyzed, the IA contributed $37 \%\left(\mathrm{R}^{2}=.37, \mathrm{~F}=87.75, \mathrm{p}<.001\right)$ of the variance and functional capacity contributed an additional $5 \%$ of the variance $\left(\mathrm{R}^{2}=.42, \quad \mathrm{~F}=53.29\right.$, $\mathrm{p}<.001)$. Finally, when social functioning and interpersonal outcomes were examined, IA contributed to $29 \%\left(\mathrm{R}^{2}=.29, \mathrm{~F}=60.51, \mathrm{p}<.001\right)$ of the variance, and functional competence contributed an additional $2 \%$ of the variance $\left(\mathrm{R}^{2}=.31, \mathrm{~F}=53.29, \mathrm{p}<.001\right)$. These results indicate that IA of neurocognition more strongly predicted non-social functional outcomes (everyday activities) than social outcomes (interpersonal relationships). Importantly, IA of neurocognition may be the strongest predictor of non-social outcome, and more predictive than either cognition or capacity. ${ }^{21}$

\section{Neurocognitive informant ratings}

Research has shown that high-contact informant ratings of patients' neurocognitive ability can be a highly useful tool for assessing functional outcomes, and a reliable proxy for extensive neurocognitive performance assessment. High-contact clinician ratings of 214 patients with 
TABLE 1. Clinical Assessment of Introspective Accuracy

\begin{tabular}{|c|c|c|c|}
\hline & Definition & Example & Reliable and Valid Measures \\
\hline Rating Scales & $\begin{array}{l}\text { Discrepancy score between high-contact } \\
\text { clinician rating and self-rating. }\end{array}$ & $\begin{array}{l}\text { A patient rates his ability to perceive the emotional states of } \\
\text { others as a } 2 \text { out of } 10 \text {, with higher ratings indicating greater } \\
\text { impairment. A high-contact clinician rates the patient at a } 9 \text {. } \\
\text { Thus, IA is } 7 \text {. Potential scores would be }-9 \text { to } 9 \text {. Scores }>0 \\
\text { denote overestimation, scores }<0 \text { denote underestimate, } \\
\text { and a score } 0 \text { denotes accurate IA. }\end{array}$ & $\begin{array}{l}\text {-Neurocognition: Cognitive Assessment } \\
\text { Inventory (CAI) }{ }^{21}, \text { Schizophrenia Cognition } \\
\text { Rating Scale (SCoRS) })^{13} \\
\text {-Social Cognition: Observable Social } \\
\text { Cognition: A Rating Scale (OSCARs) }{ }^{27}\end{array}$ \\
\hline $\begin{array}{c}\text { Performance Based } \\
\text { Measurements }\end{array}$ & $\begin{array}{l}\text { Self-assessment of performance after } \\
\text { each question or completion of } \\
\text { measure compared with objective } \\
\text { performance. }\end{array}$ & $\begin{array}{l}\text { Patients estimates they got } 80 \% \text { correct on neurocognitive } \\
\text { battery. Their actual score was } 30 \% \text {. The patient's IA would } \\
\text { be } 50 \text {. The potential range would be between }-100 \text { to } 100 \text {. }\end{array}$ & $\begin{array}{l}\text {-Neurocognition: Matrics Consensus Battery } \\
\text { B (MCCB) }{ }^{19} \\
\text {-Social Cognition: Bell Lysaker Emotion } \\
\text { Recognition Task (BLERT) }{ }^{28} \text { Penn Emotion } \\
\text { Recognition Task (ER-40) }{ }^{29} \text {. Hinting Task }{ }^{30}\end{array}$ \\
\hline
\end{tabular}

TABLE 2. Strongest Predictors of Everyday Outcomes and Patterns of Prediction by Introspective Accuracy

\begin{tabular}{lrr} 
Functional Outcome Domain & Strongest Predictor & Added Variance from IA \\
\hline Everyday Activities & IA of Neurocognition & IA of neurocognition: $\sim 40 \%$ variance, \\
& IA social cognition: not significant & IA of neurocognition: $\sim 30 \%$ variance, \\
Interpersonal Relationships & High-Contact Clinician Ratings & IA social cognition: $6 \%$ variance \\
Employment & IA of Neurocognition & IA neurocognition: $\sim 40 \%$ variance, \\
& & IA social cognition: $\sim 6-8 \%$ variance
\end{tabular}

schizophrenia on the Cognitive Assessment Inventory (CAI) showed moderate correlations to work and everyday activities (all $\mathrm{r}=-.28$ to $-.42, \mathrm{p}<.001){ }^{21}$ These correlations were similar in their magnitude to those coming from the combination of performance based assessments of cognition and scores on a functional capacity measure.

In a previous study, ratings on the Schizophrenia Cognition Rating Scale (SCoRS), based on interviewer judgment based after interviews with patients and informants, were as strongly correlated with NP test performance as performance based assessments of functional capacity. ${ }^{13}$ In a later study, informant ratings of cognitive and functional performance with the SCoRS were sensitive to effects of a pharmacological treatment (encenicline), while patient reports of their cognitive and functional performance with the same instrument did not separate from placebo. ${ }^{31}$

\section{Social cognitive objective performance}

A meta-analysis of 52 studies found that social cognitive performance-based scores had a medium strength correlation with functional outcomes (all $\mathrm{r}=.31-.48$, all $\mathrm{p}<.004)$. A subsequent analysis of the data showed that social cognitive performance had a stronger relationship to social everyday outcomes and non-social outcomes. ${ }^{6}$ The results from the SCOPE trials support the association between social cognitive measures and functional outcomes, but found the strength of the relationship to be to be small. Half of the social cognitive tasks assessed showed significant, yet limited correlations. When restricting the sample to individuals with high contact clinician informants, correlations became minimal and largely non-significant; the average correlation fell to 0.07 , and only one measure remained significant. Social cognitive performance accounted for less than $5 \%$ of the variance in social and non-social outcomes. ${ }^{16}$

\section{Social cognition informant ratings}

The Observable Social Cognition Rating Scale (OSCARS), the first informant based interview scale for social cognition, has shown internal consistency and test re-test reliability. Importantly, the OSCARS uniquely predicted real-world outcomes beyond objective social cognitive measures with a magnitude of nearly double the variance contributed by objective-based measures of social cognition. ${ }^{27}$ On-going research for the fifth phase of the SCOPE trial suggested that informant based ratings on the OSCARs might be a stronger predictor of functional outcomes than performance on social cognitive performance-based assessments. In particular, OSCARs ratings generated by informants who were unaware of any elements of test performance or self-reports accounted for a larger proportion of the variation in social outcomes (all $\mathrm{r}=.53-.63$, all $\left.\mathrm{R}^{2}=.25-36, \mathrm{p}<.001\right)$ than non-social outcomes $\left(\mathrm{r}=.38, \mathrm{R}^{2}=.14, \mathrm{p}<.001\right) .{ }^{32}$ These findings 
TABLE 3. Clinical Scenarios regarding Introspective accuracy

Scenario One

Scenario Two

\begin{tabular}{|c|c|c|}
\hline Deficits & $\begin{array}{l}\text { A person incorrectly believes they have a good memory, but actually } \\
\text { regularly forgets and has difficulty paying bills. }\end{array}$ & $\begin{array}{l}\text { A person incorrectly believes she is not good at reading others' emotions and } \\
\text { lacks the motivation to engage in social interactions. }\end{array}$ \\
\hline Cognition & $\begin{array}{l}\text { Patient has neurocognitive deficits } \\
\text { Particularly, in learning and memory }\end{array}$ & Patient does not have social cognitive deficits \\
\hline Introspective Accuracy & $\begin{array}{l}\text { Poor self-assessment of neurocognition } \\
\text { Over-estimation of neurocognitive ability }\end{array}$ & $\begin{array}{l}\text { Poor self-assessment of social cognition } \\
\square \text { Under-estimation of social cognition ability }\end{array}$ \\
\hline Functional Outcomes & $\begin{array}{l}\text { Patient displays functional deficits } \\
\text { Repeated attempts to live independently have led to adverse } \\
\text { outcomes including failures to pay rent on time }\end{array}$ & $\begin{array}{l}\text { Patient displays functional deficits } \\
\text { Patient's inaccurate IA may relate to decreased motivation or attempts to } \\
\text { engage in interpersonal communication and relationships }\end{array}$ \\
\hline
\end{tabular}

support that the 7-question OSCARs rating scale might be an effective proxy for extensive performance-based testing and may aid in determining factors producing a patients' social impairments.

IA of social cognition is an emerging research field. Recent data suggests that IA accounts for a unique variance of $6-8 \%$ in the prediction of social outcomes beyond social cognitive performance or informant ratings. IA of SC showed a significant correlation of medium strength to interpersonal, social acceptability, and work outcomes (all $\mathrm{r}=.32-.45, \mathrm{P}<.001$ ) while showing a small relationship to everyday activities $(\mathrm{r}=.23, \mathrm{P}<.001)$. These findings support the combination of high-contact informant ratings and patient's selfreports because the discrepancy score adds unique understanding of everyday social deficits. ${ }^{32}$

\section{Clinical implications}

To bring together our discussion of the relationship between neuro- and social cognition, and metacognitive IA, consider the following scenarios (Table 3). (1) A person incorrectly believes they have a good memory, but actually regularly forget tasks and has difficulty paying bills. (2) A person incorrectly believes she is not good at reading others' emotions and lacks the motivation to engage in social interactions as a consequence. In scenario one, deficits in neurocognition coupled with poor IA leads to deficits in non-social outcomes. In scenario two, the individual does not present with social cognitive deficits yet, poor IA produce interpersonal deficits. The outcome of each scenario is ultimately the same. The individual fails to complete real-world tasks. The scenarios demonstrate how cognition interacts with separate but interrelated measures leading to real-world impairments.

Evidence that subdomains of cognition (neurocognition, social cognition, IA) predict different functional outcomes opens an exciting new frontier in research and clinical treatment. Clinicians can more accurately individualize their evaluation and treatment. For example, if a patient presents with significant deficits in interpersonal relationships, a focused assessment of a patient's social cognition performance and their IA of social cognition would be most helpful. Now consider an individual that who struggles with independent living skills. Evaluation of neurocognitive test performance and their IA of neurocognition would best highlight deficits associated with non-social functional impairment. Evidence that informant ratings are useful as a standard against which to judge the accuracy of patients' self-assessments, and as a reliable proxy for extensive neuropsychological testing improves the feasibility of clinically assessing the described predictors of functional deficits. Non-social and social deficits are not mutually exclusive, but divergent patterns of prediction enhance the clinical toolbox.

\section{Disclosures}

Dr. Harvey reports personal fees from Allergan, personal fees from Akili, personal fees from Boehringer-Ingelheim, from Lundbeck, personal fees from Otsuka Digital Health, personal fees from Sanofi, personal fees from Sunovion, personal fees from Takeda, personal fees from Teva, outside the submitted work.

Ms. Silberstein has nothing to disclose.

\section{REFERENCES:}

1. Bleuler E. Dementia Praecox, or the Group of Schizophrenias. J. Zinkin, Trans: New York: International Universities Press; 1950 (Original work published 1911).

2. Bowie CR, Leung WW, Reichenberg A, et al. Predicting Schizophrenia Patients' Real-world Behavior with Specific Neuropsychological and Functional Capacity Measures. Biol Psychiatry. 2008; 63(5): 505-511.

3. Bowie CR, Reichenberg A, Patterson TL, Heaton RK, Harvey PD. Determinants of Real-world Functional Performance in Schizophrenia Subjects: Correlations with Cognition, Functional Capacity, and Symptoms. Am J Psychiatry. 2006; 163(3): 418-425.

4. Bowie CR, Depp C, McGrath JA, et al. Prediction of Real-world Functional Disability in Chronic Mental Disorders: a Comparison of Schizophrenia and Bipolar Disorder. Am J Psychiatry. 2010; 167(9): 1116-1124.

5. Harvey PD, Raykov T, Twamley EW, Vella L, Heaton RK, Patterson TL. Validating the Measurement of Real-world Functional 
Outcomes: Phase I Results of the VALERO Study. Am J Psychiatry. 2011; 168(11): 1195-1201.

6. Fett AK, Viechtbauer W, Dominguez MD, Penn DL, van Os J, Krabbendam L. The Relationship between Neurocognition and Social Cognition with Functional Outcomes in Schizophrenia: a Meta-analysis. Neuroscience Biobehav Rev. 2011; 35(3): 573-588.

7. Green MF, Kern RS, Braff DL, Mintz J. Neurocognitive Deficits and Functional Outcome in Schizophrenia: Are We Measuring the "Right Stuff"? Schizophr Bull. 2000; 26(1): 119-136.

8. Tabares-Seisdedos R, Balanza-Martinez V, Sanchez-Moreno J, et al. Neurocognitive and Clinical Predictors of Functional Outcome in Patients with Schizophrenia and Bipolar I Disorder at One-year Follow-up. J Affect Disord. 2008; 109(3): 286-299.

9. Brekke JS, Levin S, Wolkon GH, Sobel E, Slade E. Psychosocial Functioning and Subjective Experience in Schizophrenia. Schizophr Bull. 1993; 19(3): 599-608.

10. Pinkham AE, Penn DL, Green MF, Buck B, Healey K, Harvey PD. The Social Cognition Psychometric Evaluation Study: Results of the Expert Survey and RAND Panel. Schizophr Bull. 2014; 40(4): 813-823.

11. Gold JM, Barch DM, Carter CS, et al. Clinical, Functional, and Intertask Correlations of Measures Developed by the Cognitive Neuroscience Test Reliability and Clinical Applications for Schizophrenia Consortium. Schizophr Bull. 2012; 38(1): 144-152.

12. Knowles EE, Weiser M, David AS, Glahn DC, Davidson M, Reichenberg A. The Puzzle of Processing Speed, Memory, and Executive Function Impairments in Schizophrenia: Fitting the Pieces Together. Biol Psychiatry. 2015; 78(11): 786-793.

13. Keefe RS, Poe M, Walker TM, Kang JW, Harvey PD. The Schizophrenia Cognition Rating Scale: an Interview-based Assessment and Its Relationship to Cognition, Real-world Functioning, and Functional Capacity. Am J Psychiatry. 2006; 163 (3): 426-432.

14. McClure MM, Bowie CR, Patterson TL, et al. Correlations of Functional Capacity and Neuropsychological Performance in Older Patients with Schizophrenia: Evidence for Specificity of Relationships? Schizophr Res. 2007; 89(1-3): 330-338.

15. Depp CA, Mausbach BT, Harmell AL, et al. Meta-analysis of the Association between Cognitive Abilities and Everyday Functioning in Bipolar Disorder. Bipolar Disord. 2012; 14(3): 217-226.

16. Pinkham AE, Penn DL, Green MF, Harvey PD. Social Cognition Psychometric Evaluation: Results of the Initial Psychometric Study. Schizophr Bull. 2016; 42(2): 494-504.

17. Sabbag S, Twamley EM, Vella L, Heaton RK, Patterson TL, Harvey PD. Assessing Everyday Functioning in Schizophrenia: Not All Informants Seem Equally Informative. Schizophr Research. 2011; 131(1-3): 250-255.

18. Harvey PD, Sabbag S, Prestia D, Durand D, Twamley EW, Patterson TL. Functional Milestones and Clinician Ratings of Everyday Functioning in People with Schizophrenia: Overlap between
Milestones and Specificity of Ratings. J Psychiatric Res. 2012; 46 (12): 1546-1552.

19. Nuechterlein KH, Green MF, Kern RS, et al. The MATRICS Consensus Cognitive Battery, Part 1: Test Selection, Reliability, and Validity. Am J Psychiatry. 2008; 165(2): 203-213.

20. Koren D, Seidman LJ, Goldsmith M, Harvey PD. Real-world Cognitive and Metacognitive Dysfunction in Schizophrenia: A New Approach for Measuring (and Remediating) More of the "Right Stuff". Schizophr Bull. 2006; 32(2): 310-326.

21. Gould F, McGuire LS, Durand D, et al. Self-assessment in Schizophrenia: Accuracy of Evaluation of Cognition and Everyday Functioning. Neuropsychology. 2015; 29(5): 675-682.

22. McKibbin C, Patterson TL, Jeste DV. Assessing Disability in Older Patients with Schizophrenia: Results from the WHODAS-II. J Nerv Ment Dis. 2004; 192(6): 405-413.

23. Green MF, Schooler NR, Kern RS, et al. Evaluation of Functionally Meaningful Measures for Clinical Trials of Cognition Enhancement in Schizophrenia. Am J Psychiatry. 2011; 168(4): 400-407.

24. Holshausen K, Bowie CR, Mausbach BT, Patterson TL, Harvey PD. Neurocognition, Functional Capacity, and Functional outcomes: the Cost of Inexperience. Schizophr Res. 2014; 152(2-3): 430-434.

25. Patterson TL, Semple SJ, Shaw WS, et al. Self-Reported Social Functioning Among Older Patients with Schizophrenia. Schizophr Res. 1997; 27(2-3): 199-210.

26. Harvey PD, Khan AK, Keefe RS. Using the PANNS to Define Different Domains of Negative Symptoms: Prediction of Everyday Functioning by Impairments in Emotional Expression and Emotional Experience. Innov Clin Neurosci. 2017; 14(11-12): 18-22.

27. Healey KM, Combs DR, Gibson CM, Keefe RS, Roberts DL, Penn DL. Observable Social Cognition-A Rating Scale: an Interview-Based Assessment for Schizophrenia. Cognitive Neuropsychiatry. 2015; 20 (3): 198-221.

28. Bryson G, Bell M, Lysaker P. Affect recognition in schizophrenia: a function of global impairment or a specific cognitive deficit. Psychiatry Res. 1997; 71(2): 105-113.

29. Kohler CG, Turner TH, Bilker WB, et al. Facial emotion recognition in schizophrenia: intensity effects and error pattern. $\mathrm{Am} \mathrm{J}$ Psychiatry. 2003; 60(10): 1768-1774

30. Corcoran R, Mercer G, Frith CD. Schizophrenia, symptomatology and social inference: investigating "theory of mind" in people with schizophrenia. Schizophr Res. 1995; 17(1): 5-13.

31. Keefe RS, Davis VG, Spagnola NB, et al. Reliability, Validity and Treatment Sensitivity of the Schizophrenia Cognition Rating Scale. Eur Psychopharmacol. 2015; 25(2): 176-184.

32. Silberstein J. M., Pinkham A. E., Penn D. L., \& Harvey P. D. Selfassessment of social cognitive ability in schizophrenia: Association with social cognitive test performance, informant assessments of social cognitive ability, and everyday outcomes. Schizophr Res. doi:10.1016/j.schres.2018.04.015 epub before publication 